\title{
Prediction accuracy of selected spatial interpolation methods for soil texture at farm field scale
}

\author{
D. Gozdowski ${ }^{1 *}$, M. Stępieńn ${ }^{2}$, S. Samborski ${ }^{2}$, E.S. Dobers ${ }^{3}$, J. Szatyłowicz ${ }^{4}, J_{\text {. Chormański }}{ }^{5}$
}

${ }^{1}$ Department of Experimental Design and Bioinformatics, Warsaw University of Life Sciences, Nowoursynowska 159, 02-776 Warsaw, Poland. *Corresponding author: dariusz_gozdowski@sggw.pl. ${ }^{2}$ Department of Agronomy, Warsaw University of Life Sciences, Nowoursynowska 159,02-776 Warsaw, Poland.email: michal1966@gmail. com. ${ }^{3} \mathrm{Ag}$-GeoData, NikolausbergerWeg 63,D-37073 Göttingen, Germany.email: stefan.dobers@ag-geodata. de. ${ }^{4}$ Department of Environmental Improvement, Warsaw University of Life Sciences, Nowoursynowska 159, 02-776 Warsaw, Poland. email: jan_szatylowicz@sggw.pl. ${ }^{5}$ Department of Hydraulic Engineering, Warsaw University of Life Sciences, Nowoursynowska 159,02-776 Warsaw, Poland.email: j.chormanski@levis.sggw.pl

\begin{abstract}
Soil texture was examined in four crop fields with areas of 10 to 45 ha located in northern and central Poland. In each field, from 21 to 60 soil samples were collected using stratified sampling. The content (\%) of soil particles, i.e., sand, silt and clay, was then evaluated using laboratory methods. The apparent electrical conductivity (ECa) was measured and used as ancillary data for the interpolation of soil texture. The obtained data were used to compare selected spatial interpolation methods according to the accuracy of prediction. The examined methods were evaluated based on the results of cross-validation tests. Two methods of validation were used: leave-oneout cross-validation and validation based on a test set of points, with approximately $30 \%$ randomly selected. The smallest root mean square error (RMSE) for the prediction of sand, silt and clay was observed for ordinary cokriging in which ECa was used as a covariate. The other three methods, i.e., inverse distance weighting, radial basis functioning and ordinary kriging, had very similar RMSE values, which were approximately $10 \%$ higher compared to ordinary cokriging.
\end{abstract}

Keywords: Geostatistics, kriging, soil fractions, soil texture, spatial interpolation 


\section{Introduction}

Accurate prediction of soil texture (ST) is very important in precision farming because soil texture has a great influence on soil productivity (Buckman and Brady, 1971; Mzuku et al., 2005; He et al., 2013; Gozdowski et al., 2014) and several other properties that influence agricultural potential (Buckman and Brady, 1971; White, 1997; Dec and Dörner 2014). Therefore, ST is considered a main factor for delineating management zones in precision farming. There are several methods for determining ST (Bieganowski and Ryżak, 2011). The simplest method is known as the "feel method," which is based on soil manipulation by hand; therefore, the results are dependant on the specific skills of the researcher. More reliable methods of soil texture classification are based on particle size analysis, i.e., relative amounts of sand, silt and clay. However, these methods are time consuming, and the estimation of ST with high spatial resolution is not commonly performed at farm level. Proximal sensing methods for ST prediction based on satellite imagery or soil electrical conductivity are promising but still not accurate (Mulder et al., 2011; RodríguezPérez et al., 2011). Correlations between information from multispectral images and soil fractions (e.g., sand content) are quite strong, but the mean error of prediction is still too high (approximately 15\%) (Masselli et al., 2008). Usefulness of apparent electrical conductivity (ECa) for ST estimation is limited by a high error of prediction of several percentage points (Rodríguez-Pérez et al. 2011), but ECa can be treated as ancillary data in ST mapping. Because of these limitations, the spatial interpolation of sand, silt and clay determined with direct laboratory methods is required to create a map of ST for an entire farm field.

The results of spatial interpolation of any soil property can vary by a high degree depending on the method of interpolation (Robinson and Metternicht,
2006; González et al. 2014). Therefore, only spatial interpolation methods producing the highest accuracy of prediction are desirable among the wide range of interpolation techniques available. Selecting the most efficient and accurate interpolation method for predicting soil properties has been the subject of numerous studies (e.g., Kravchenko and Bullock, 1999; Robinson and Metternicht, 2006; Zhu and Lin 2010), which evaluated the efficacy of techniques in measuring soil properties such as nutrient content (mainly $\mathrm{K}$ and $\mathrm{P}$ ), organic matter content and $\mathrm{pH}$; however, few of the techniques were actually related to soil texture interpolation (e.g., Meul and Van Meirvenne, 2003; Karydas et al., 2009; Ließ et al., 2012). Moreover, not all surveys were conducted at the farm-field scale, as certain surveys conducted at a regional scale where local spatial variability is omitted.

The purpose of this study is to evaluate the ST prediction accuracy of selected spatial interpolation methods at the farm-field scale, and the main criteria by which prediction accuracy is estimated are the results of cross-validation analysis.

\section{Materials and Methods}

\subsection{Research site and soil sampling}

Four farm fields were examined for the years 20092011. Two of the fields (D2 and D5) were located in northern Poland, and two others (O3a and $\mathrm{O} 5 \mathrm{c})$ were located in central Poland. Characteristics of field locations and soil types are presented in Table 1.

Undisturbed soil samples were collected, and one composite "point" soil sample consisted of three 100 cm3 cylinders that were collected at a depth of 15$20 \mathrm{~cm}$ and then subjected to chemical and physical analyses, including ST analysis. A stratified sam- 
pling design was used, and the sampling locations for this study were designed using soil map information from maps at a scale of 1:5000 and aerial photographs from archives. The sampling points were established in areas that were typical for the surrounding area. The sampling points are named 'centroids' because they represent the geographical centre of the sampling transects. The percentage of sand $(0.05-2.00 \mathrm{~mm})$, silt $(0.002-0.05 \mathrm{~mm})$ and clay $(<0.002 \mathrm{~mm})$ content was measured using the aerometric method of Casagrande that was modified by Prószyński (PN-R-4033).

The apparent electrical conductivity $(\mathrm{mS} / \mathrm{m})$ was treated as a covariate and was measured using an EM 38 (Geonics $\left.{ }^{\circledR}\right)$ in horizontal $\left(\mathrm{EC}_{\mathrm{aH}}\right)$ or vertical $\left(\mathrm{EC}_{\mathrm{aV}}\right)$ dipole mode at a depth of approximately 0.75 $\mathrm{m}$ or $1.5 \mathrm{~m}$, respectively.

\subsection{Statistical analysis}

The spatial dependence of the attributes was evaluated on the basis of variogram parameters for spherical function and Moran's I autocorrelation coefficient. The interpolation method accuracy was evaluated on the basis of the root mean square error (RMSE) for cross-validation using the following two methods:

1) Leave-one-out cross-validation (LOOCV), in which each single observation from the sample was treated as the validation point and the remaining points were treated as the training set;

2) Validation based on a test set of points, with approximately $30 \%$ randomly selected and the remaining $70 \%$ treated as a training set (Figure 1).

Four interpolation methods were evaluated:

1) Inverse distance weighting (IDW), where the power parameter was optimised to obtain the smallest prediction error;

2) Radial basis function (RBF), where the completely regularised spline was the basis function;
3) Ordinary kriging (OK), where the spherical function was used for theoretical variogram modelling; and

4) Ordinary cokriging (OCK), where the spherical variogram was used and $\mathrm{EC}_{\mathrm{aH}}$ and $\mathrm{EC}_{\mathrm{aV}}$ (measured using horizontal and vertical modes) were treated as covariates.

Non-spatial statistical analyses were conducted using Statistica 10 (StatSoft, 2011) software, and spatial statistics and maps were prepared in ArcGIS 9.3 (ESRI 2009). The significance level for all analyses was set at 0.05 .

\section{Results}

The prevailing ST class for two examined fields located in northern Poland was sandy loam and the two fields located in central Poland was loamy sand (Table 1). The largest spatial variability of ST fractions (sand, silt and clay) was observed in the field D5 where even neighbouring soil samples often had significantly different contents in the ST fractions. For that reason, field spatial Moran's I autocorrelation coefficient for field D5 was close to zero for all three soil fractions (Table 2). Other types of spatial variability in ST fractions were observed for fields D2 and $\mathrm{O} 3 \mathrm{a}$, where strong spatial autocorrelation for sand and silt content was observed. The spatial autocorrelation was positive, which means that for neighbouring sampling points, these two ST fractions were related. The exception were some very close sampling points for field O3a which had very big differences between silt content, which is presented on experimental variogram (Figure 2). Only the clay content had a weak spatial dependence, likely because relatively small clay content was found.

Stronger positive spatial autocorrelation allows better prediction efficiency of soil properties during spatial interpolation procedures. 
Table 1. Characteristics of the examined fields

\begin{tabular}{|c|c|c|c|c|}
\hline \multirow{2}{*}{$\begin{array}{l}\text { Name of the field } \\
\text { Location }\end{array}$} & $\mathrm{D} 2$ & D5 & O3a & $\mathrm{O} 5 \mathrm{c}$ \\
\hline & Northern Polan & Pomerania & $\begin{array}{l}\text { Central Poland } \\
\text { Lowland }\end{array}$ & Mazovia \\
\hline \multirow{2}{*}{$\begin{array}{l}\text { Area } \\
\text { Geographic coordinates }\end{array}$} & 21.9 ha & 45.0 ha & 10.5 ha & 10.4 ha \\
\hline & $\begin{array}{l}54^{\circ} 31^{\prime} 13^{\prime \prime N} \\
17^{\circ} 18^{\prime} 33^{\prime \prime} \mathrm{E}\end{array}$ & $\begin{array}{l}54^{\circ} 32^{\prime} 18^{\prime \prime} \mathrm{N} \\
17^{\circ} 17^{\prime} 55^{\prime \prime} \mathrm{E}\end{array}$ & $\begin{array}{l}52^{\circ} 4^{\prime} 54^{\prime \prime} \mathrm{N} \\
21^{\circ} 8^{\prime} 32^{\prime \prime} \mathrm{E}\end{array}$ & $\begin{array}{l}52^{\circ} 4^{\prime} 44^{\prime \prime} \mathrm{N} \\
21^{\circ} 8^{\prime} 9^{\prime \prime} \mathrm{E}\end{array}$ \\
\hline \multirow{2}{*}{$\begin{array}{l}\text { Altitude (a.s.1.) } \\
\text { Date of soil sample } \\
\text { collection }\end{array}$} & $48-61 \mathrm{~m}$ & $62-70 \mathrm{~m}$ & $89-91 \mathrm{~m}$ & $102-105 \mathrm{~m}$ \\
\hline & $\begin{array}{l}\text { September } \\
2009\end{array}$ & March 2011 & $\begin{array}{l}\text { November } \\
2009\end{array}$ & October 2009 \\
\hline $\begin{array}{l}\text { Predominant soil type } \\
\text { (WRB 1998*) }\end{array}$ & $\begin{array}{l}\text { Dystric } \\
\text { Cambisols }\end{array}$ & $\begin{array}{l}\text { Dystric } \\
\text { Cambisols }\end{array}$ & $\begin{array}{l}\text { Dystric } \\
\text { Arenosols, } \\
\text { Phaeozems }\end{array}$ & $\begin{array}{l}\text { Albeluvisols } \\
\text { and Luvisols }\end{array}$ \\
\hline Prevailing soil texture & Sandy loam & Sandy loam & Loamy sand & Loamy sand \\
\hline \multirow{3}{*}{$\begin{array}{l}\text { Range of } \\
\text { content }(\%)\end{array}$} & $59-83$ & $56-81$ & $66-89$ & $74-90$ \\
\hline & $13-32$ & $15-36$ & $9-29$ & $9-22$ \\
\hline & $3-11$ & $4-12$ & $0-5$ & $0-6$ \\
\hline $\begin{array}{l}\text { Number of sampling } \\
\text { points }\end{array}$ & 58 & 60 & 22 & 21 \\
\hline $\begin{array}{l}\text { Number of soil samples } \\
\text { in training and test sets }\end{array}$ & $40 / 18$ & $42 / 18$ & $15 / 7$ & $14 / 7$ \\
\hline
\end{tabular}

* Approximate WRB equivalent of soil type relating to the Polish classification from 1989 and based on Charzyński (2006) and the authors' own elaboration

In Tables 3 and 4, values of the RMSE, which is an indicator of the prediction accuracy of spatial interpolation, are presented. For field D5, RMSE values were much higher compared to the other three fields because of a lack of spatial dependence. The range of ST fractions affected RMSE values, as shown by the sand content; the highest range was characterised by the lowest RMSE and the clay content followed the opposite trend. Comparisons of RMSE values for the four examined interpolation methods using the two validation methods produced similar results. For almost all the fields and each of the ST fractions, the smallest RMSE was achieved by using ordinary cokriging in which the $\mathrm{EC}_{\mathrm{aH}}$ and $\mathrm{EC}_{\mathrm{aV}}$ were treated as covariates (Figure 3 presents predicted silt content on the basis of LOOCV). For the LOOCV method, the prediction accuracy expressed as RMSE was approximately 0.3 $0.5 \%$ lower for sand and clay, it means that the RMSE was relatively c.a. $10 \%$ lower. In the case of soil clay content, the RMSE was approximately $0.1 \%$ lower for cokriging in comparison with the other three interpolation methods. Validation results based on a test set of points where approximately $30 \%$ of the points were randomly selected from all of the sampling points were quite similar to the results based on LOOCV, and the relative RMSE value was approximately $10 \%$ lower in comparison to the other interpolation methods. This result indicates that the ancillary information of soil electrical conductivity $\left(\mathrm{EC}_{\mathrm{aH}}\right.$ and $\left.\mathrm{EC}_{\mathrm{aV}}\right)$ is useful for predictions for all of the ST fractions. 

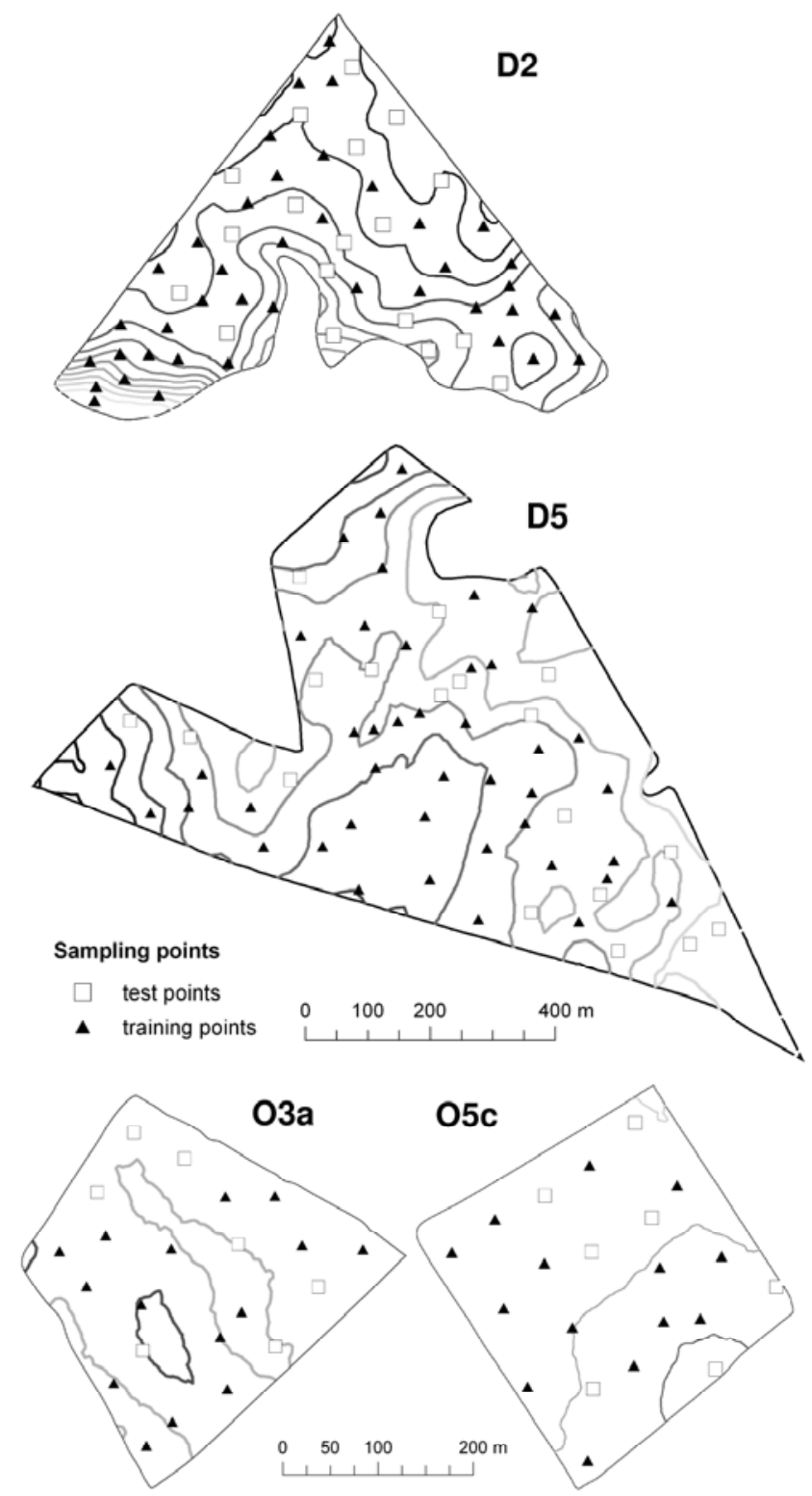

Figure 1. Maps of four examined fields (D2, D5, O3a and O5c) with sampling points divided into training and test sets and isohypses superimposed on $1 \mathrm{~m}$ of elevation. 
Table 2. Parameters of variogram (spherical function) and spatial autocorrelation (Moran's I) for soil fractions.

\begin{tabular}{|c|c|c|c|c|}
\hline & D2 & D5 & $\mathrm{O} 3 \mathrm{a}$ & $\mathrm{O} 5 \mathrm{c}$ \\
\hline & \multicolumn{4}{|c|}{ Sand (\%) } \\
\hline Nugget effect & 11.7 & 17.5 & 18.0 & 2.9 \\
\hline Partial sill & 30.0 & 8.2 & 13.3 & 17.7 \\
\hline Range (m) & 592 & 212 & 209 & 283 \\
\hline Moran's $I$ & $0.61 *$ & -0.06 & $0.58 *$ & $0.39^{*}$ \\
\hline \multicolumn{5}{|c|}{ Silt $(\%)$} \\
\hline Nugget effect & 6.6 & 8.2 & 12.2 & 4.1 \\
\hline Partial sill & 20.7 & 8.6 & 10.4 & 11.2 \\
\hline Range (m) & 560 & 191 & 195 & 308 \\
\hline Moran's I & $0.64 *$ & 0.07 & $0.48^{*}$ & 0.26 \\
\hline \multicolumn{5}{|c|}{ Clay $(\%)$} \\
\hline Nugget effect & 2.6 & 0.9 & 0.0 & 2.9 \\
\hline Partial sill & 0.9 & 3.3 & 2.5 & 0.0 \\
\hline Range (m) & 699 & 41 & 136 & 352 \\
\hline Moran's I & $0.27^{*}$ & -0.12 & 0.29 & -0.07 \\
\hline
\end{tabular}

$* P<0.05$

Differences in terms of RMSE values for the other three interpolation techniques, IDW, RBF and OK, were very small. Because there were similar RMSE values for all the examined interpolation techniques, indicating that the best interpolation method that did not use covariates, was difficult. RBF was slightly more accu- te for sand content predictions compared to IDW and OK, while IDW was slightly more accurate for clay content estimations. However, the relative differences between the RMSE values for these three methods were not higher than $6 \%$, with the average ranging from $3-4 \%$ and a lack of consistency found for all fields. 

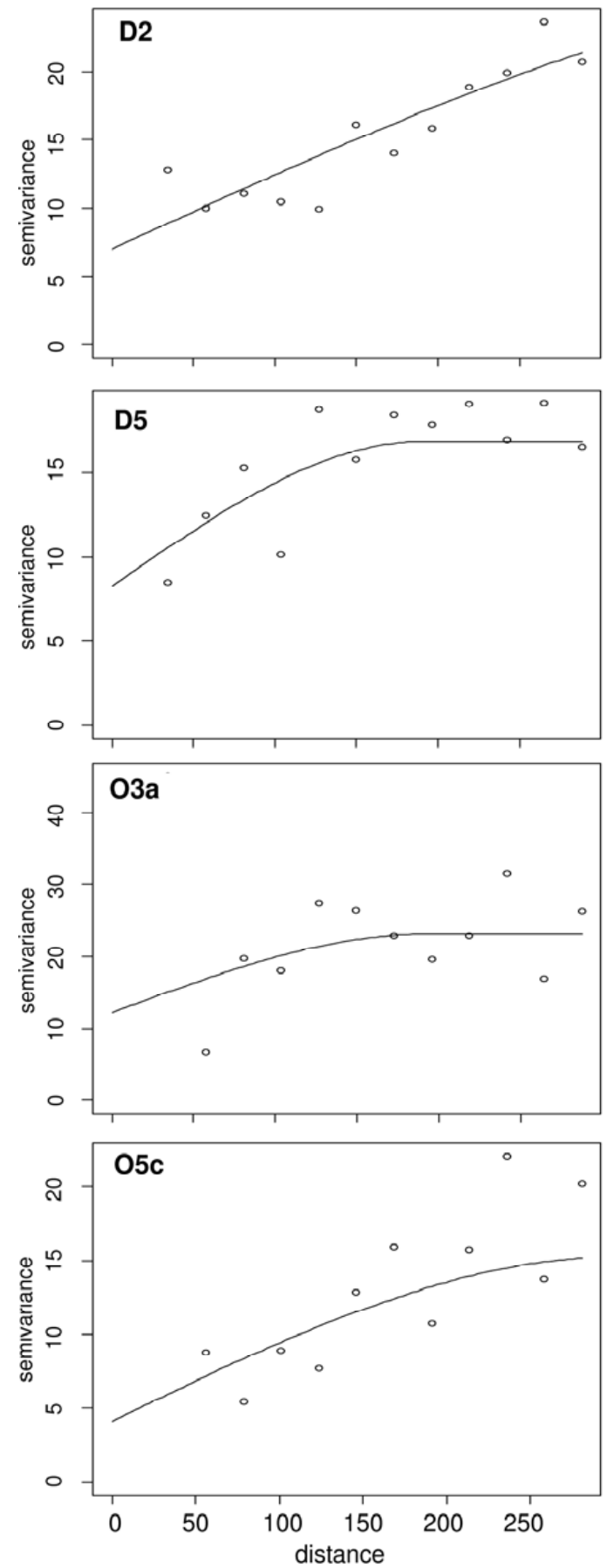

Figure 2. Experimental and theoretical variograms (spherical function) for silt content (\%) in examined fields (D2, D5, O3a and O5c) 
Table 3. Root mean square errors for cross-validation of ST based on the leave-one-out of method in four examined fields

\begin{tabular}{lccccc}
\hline & D2 & D5 & O3a & O5c & \\
\cline { 2 - 4 } & & & Sand & \\
IDW & 4.09 & 5.31 & 4.28 & 3.53 & 4.30 \\
RBF & 4.10 & 5.51 & 3.76 & 3.38 & 4.19 \\
Ordinary & 4.11 & 5.37 & 4.30 & 3.27 & 4.26 \\
kriging & & & & & \\
Cokriging & 4.00 & 4.96 & 3.80 & 2.78 & 3.88 \\
& & & Silt & & \\
IDW & 3.30 & 4.21 & 3.89 & 3.23 & 3.66 \\
RBF & 3.31 & 4.27 & 3.78 & 3.07 & 3.61 \\
Ordinary & 3.24 & 4.23 & 4.48 & 2.97 & 3.73 \\
kriging & & & & & \\
Cokriging & 3.30 & 4.38 & 3.53 & 2.43 & 3.41 \\
IDW & 1.45 & 2.19 & Clay & & \\
RBF & 1.52 & 2.32 & 1.38 & 1.82 & 1.71 \\
Ordinary & 1.58 & 2.22 & 1.36 & 1.89 & 1.77 \\
kriging & & & & 1.80 & 1.74 \\
Cokriging & 1.52 & 1.91 & 1.40 & 1.78 & 1.65 \\
\hline
\end{tabular}

Table 4. Root mean square errors for cross-validation of ST fractions based on a test set of points, with approximately $30 \%$ randomly selected.

\begin{tabular}{lccccc}
\hline & & \multicolumn{2}{c}{ Field } & Mean \\
& D2 & D5 & O3a & O5c & \\
\cline { 2 - 5 } & & & Sand & & \\
IDW & 4.32 & 5.12 & 4.29 & 3.55 & 4.32 \\
RBF & 4.04 & 5.41 & 3.85 & 3.30 & 4.15 \\
Ordinary kriging & 4.06 & 5.45 & 4.22 & 3.23 & 4.24 \\
Cokriging & 4.07 & 5.46 & 4.27 & 1.68 & 3.87 \\
& & & Silt & & \\
IDW & 3.74 & 3.90 & 3.59 & 3.15 & 3.59 \\
RBF & 3.61 & 4.00 & 3.15 & 2.86 & 3.40 \\
Ordinary kriging & 3.53 & 4.02 & 3.00 & 2.93 & 3.37 \\
Cokriging & 3.55 & 4.00 & 3.05 & 2.20 & 3.20 \\
& & & Clay & & \\
IDW & 1.26 & 2.23 & 1.82 & 1.99 & 1.83 \\
RBF & 1.25 & 2.30 & 2.10 & 2.09 & 1.94 \\
Ordinary kriging & 1.43 & 2.24 & 1.79 & 2.14 & 1.90 \\
Cokriging & 1.42 & 2.19 & 1.74 & 1.71 & 1.76 \\
\hline
\end{tabular}



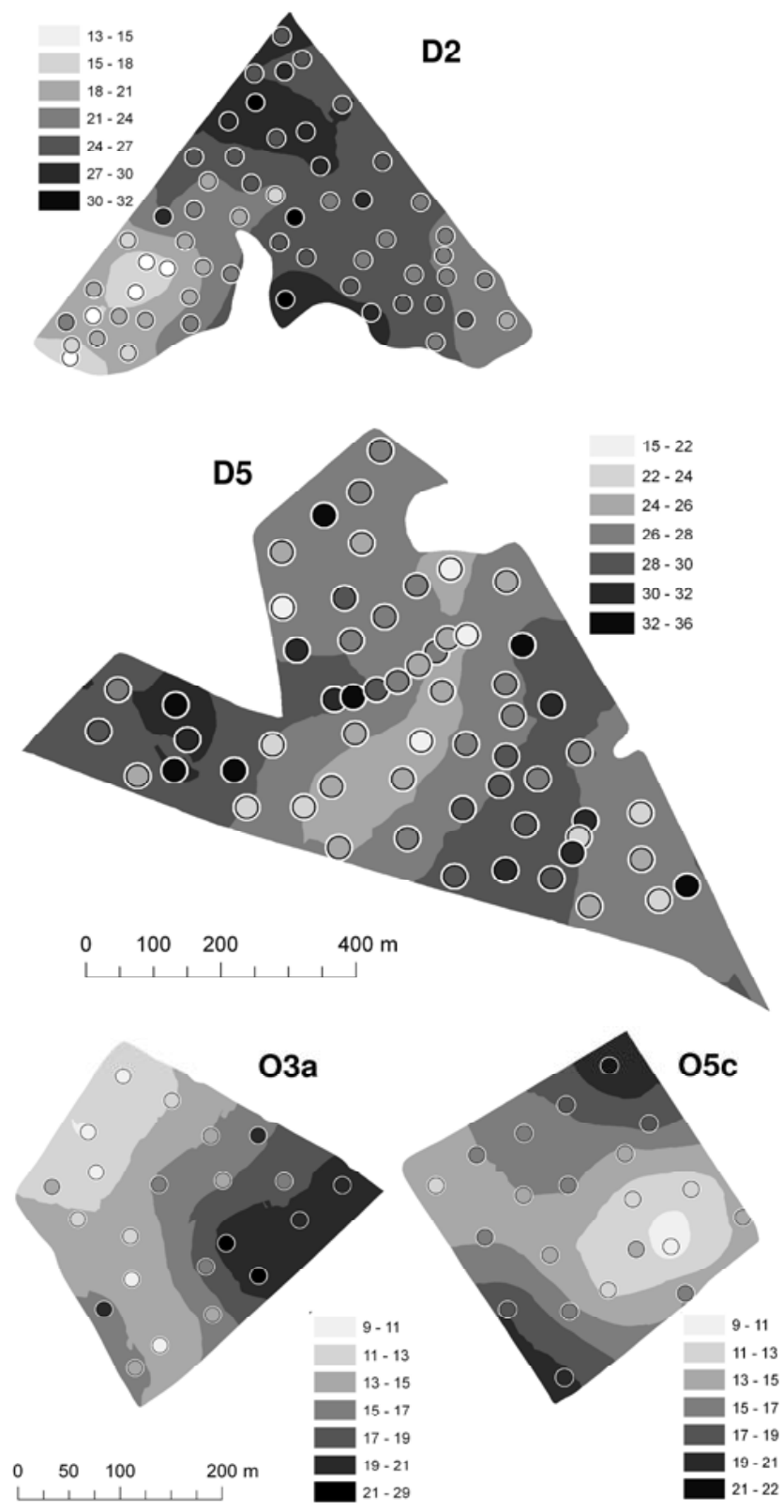

Figure 3. Maps of predicted silt (\%) content based on the ordinary cokriging method for four examined fields (D2, D5, O3a and O5c), with sampling points presenting measured silt content. 


\section{Discussion}

At least a dozen spatial interpolation methods are commonly used for spatial prediction of attributes in environmental studies. The most frequently used are the inverse distance weighting, ordinary kriging and ordinary cokriging (Li and Heap, 2011). Measures for assessing the performance of the spatial interpolation methods are based on prediction errors such as the RMSE. A review presented by Li and Heap (2011) that compared spatial interpolation methods revealed that for agriculture and soil science, methods that showed the best performance were ordinary kriging, regression kriging, kriging with an external drift and ordinary cokriging. In general, geostatistical methods (e.g., kriging) were more frequently recommended than non-geostatistical methods (e.g., IDW).

In our study, the interpolation method that produced the smallest RMSE was ordinary cokriging when $\mathrm{EC}_{\mathrm{aH}}$ and $\mathrm{EC}_{\mathrm{aV}}$ were treated as covariates. This finding is consistent with Delin et al. (2002), who found that ECa as a covariate had a strong effect on the accuracy of the spatial interpolation of clay content. In our study, prediction accuracy expressed by the RMSE was approximately $10 \%$ more accurate for sand, clay and silt when using cokriging compared to the other interpolation techniques. However, in the study by Delin and Söderström (2002), the RMSE when using cokriging was much higher for clay, at approximately $50 \%$, and as the authors indicated, fields with smaller differences in the fraction content have a less significant correlation between EC and clay, which is exactly what was found in our study. Moreover, 3 of the fields (D2, D5 and $\mathrm{O5c}$ ) in the present study are characterised by a subsoil that is finer (i.e., containing more clay) than the plough layer. There is also great variability within the fields, especially within the fields D2 and O5c, where the subsoil varies from sand to loam. Only the $\mathrm{O} 3 \mathrm{a}$ field has a relatively uniform texture in the soil pro- file. In our study, the ECa was measured in 75 or 150 $\mathrm{cm}$ of the soil layer, the soil texture was systematically determined only in upper layer, and the subsoil was verified by soil-agricultural maps and evaluated with field methods consisting of several augerings. This was likely another cause of the smaller effect of ECa as a covariate affecting the accuracy of spatial interpolation of clay and other fractions.

In a similar study on interpolation methods, Karydas et al. (2009) compared three spatial interpolation methods (i.e., OK, IDW and RBF) for their ability to predict various soil properties (e.g., clay content) at a farm-field scale. The prediction efficiencies of the methods were all very similar, and the smallest RMSE was observed with RBF, but the relative difference between the remaining two methods based on the ratio of RMSE values was less than 5\%. This result indicates that all three methods have virtually the same level of prediction accuracy, and only small differences were observed between the various spatial interpolation methods for mapping soil properties.

Results from many studies confirm that ancillary variables are important sources of information and provide more accurate predictions of soil properties at the farmfield scale (Triantafilis et al., 2001; López-Granados et al., 2005; Wetterlind et al., 2008; Goovaerts and Kerry, 2010; Akumu, 2015). In recent years, these ancillary variables have been collected using on-the-go sensors or remote sensing methods and can then be used in geostatistical models for such interpolations methods as regression kriging and ordinary cokriging. Interpolation of soil properties without ancillary variables leads to higher errors of prediction.

\section{Conclusions}

Differences in prediction accuracy of soil texture values between interpolation techniques (inverse distance weight, radial basis function and ordinary 
kriging) that do not use ancillary data were very small; therefore, selection of the best interpolator from the above methods was impossible. All soil texture fractions were predicted with similar accuracy using these three interpolation methods, but our results show that ordinary cokriging produced a higher level of prediction accuracy for all soil texture fractions compared to the inverse distance weight, radial basis function and ordinary kriging interpolation methods. Ancillary data such as apparent electrical conductivity of soil decreased the root mean square standard error values for all soil particles content mapped at the farm field scale, and such data should be used if they are available. It means that strongly correlated variable which can be measured at high spatial resolution significantly improve spatial prediction of soil texture when it is used as covariate in cokriging interpolation. It is very important because it is possible to limit number of laboratory analyses of soil samples for soil texture.

\section{Acknowledgements}

This research was supported by the Polish Ministry of Science and Higher Education project NN 310 089036 in years 2009-2012

\section{References}

Akumu, C.E., Johnson, J.A., Etheridge, D., Uhlig, P., Woods, M., Pitt, D.G., McMurray, S. 2015. GISfuzzy logic based approach in modeling soil texture: Using parts of the Clay Belt and Hornepayne region in Ontario Canada as a case study. Geoderma. 239, 13-24.

Bieganowski, A., Ryżak, M. 2011. Soil Texture: Measurement Methods. In: Encyclopedia of Agrophysics Springer Netherlands, pp: 791-794.
Buckman, HO, Brady, NC. 1960. The Nature and Properties of Soils. New York: Macmillan.

Charzyński, P. 2006. Testing WRB on Polish Soils. Toruń. APAE.

Dec, D., Dörner, J. 2014. Spatial variability of the hydraulic properties of a drip irrigated andisol under blueberries. J. Soil Sci. Plant Nutr. 14(3), 589-601.

Delin, S., Söderström, M. 2002. Performance of soil electrical conductivity and different methods for mapping soil data from a small dataset. Acta Agr. Scand. B P-S. 52, 127-135.

González, I., Neaman, A., Rubio, P., Cortés, A. 2014. Spatial distribution of copper and $\mathrm{pH}$ in soils affected by intensive industrial activities in Puchuncaví and Quintero, central Chile. J. Soil Sci. Plant Nutr. 14, 943-953.

Goovaerts, P., Kerry, R. 2010. Using ancillary data to improve prediction of soil and crop attributes in precision agriculture, in: Oliver M.A. (ed.) Geostatistical Applications for Precision Agriculture, Springer, pp: 167-194.

Gozdowski, D., Stępień, M., Samborski, S., Dobers, E.S., Szatyłowicz, J., Chormański, J. 2014. Determination of the most relevant soil properties for the delineation of management zones in production fields. Commun Soil Sci Plan. 45(17), 22892304.

He, Y., Wei, Y., DePauw, R., Qian, B., Lemke, R., Singh, A., Cuthbert R., McConkey B., Wang, H. 2013. Spring wheat yield in the semiarid Canadian prairies: Effects of precipitation timing and soil texture over recent 30 years. Field Crop. Res. 149, 329-337.

Karydas, C.G., Gitas, I.Z., Koutsogiannaki, E., Lydakis-Simantiris, N., Silleos, G.N. 2009. Evaluation of spatial interpolation techniques for mapping agricultural topsoil properties in Crete. EARSeL eProceedings. 8, 26-39. 
Kravchenko, A., Bullock, D.G. 1999. A comparative study of interpolation methods for mapping soil properties. Agron. J. 91, 393-400.

Li, J., Heap, A.D. 2011. A review of comparative studies of spatial interpolation methods in environmental sciences: Performance and impact factors. Ecol. Inform. 6, 228-241.

Ließ, M., Glaser, B., Huwe, B. 2012. Uncertainty in the spatial prediction of soil texture: Comparison of regression tree and random forest models. Geoderma. 170, 70-79.

López-Granados, F., Jurado-Expósito, M., Peña-Barragán, J.M., García-Torres, L. 2005. Using geostatistical and remote sensing approaches for mapping soil properties. Eur. J. Agron. 23, 279-289.

Maselli, F., Gardin, L., Bottai, L. 2008. Automatic mapping of soil texture through the integration of ground, satellite and ancillary data. Int. J. Remote Sens. 29, 5555-5569.

Meul, M., Van Meirvenne, M. 2003. Kriging soil texture under different types of nonstationarity. Geoderma. 112, 217-233.

Mulder, V.L., De Bruin, S., Schaepman, M.E., Mayr, T.R. 2011. The use of remote sensing in soil and terrain mapping-A review. Geoderma. 162, $1-19$.
Mzuku, M., Khosla, R., Reich, R., Inman, D., Smith, F., MacDonald, L. 2005. Spatial variability of measured soil properties across site-specific management zones. Soil Sci. Soc. Am. J. 69, $1572-1579$.

Robinson, T.P., Metternicht, G. 2006. Testing the performance of spatial interpolation techniques for mapping soil properties. Comput. Electron. Agr. 50, 97-108.

Rodríguez-Pérez, J.R., Plant, R.E., Lambert, J.J., Smart, D.R. 2011. Using apparent soil electrical conductivity (ECa) to characterize vineyard soils of high clay content. Precis. Agric. 12, 775-794.

Triantafilis, J., Huckel, A.I., Odeh, I.O.A. 2001 Comparison of statistical prediction methods for estimating field-scale clay content using different combinations of ancillary variables. Soil Sci. $166,415-427$

Wetterlind, J., Stenberg, B., Söderström, M. 2008 The use of near infrared (NIR) spectroscopy to improve soil mapping at the farm scale. Precis. Agric. 9, 57-69.

White, R.E. 1997. Principles and Practice of Soil Science: The Soil as a Natural Resource. 4th ed. Blackwell.

Zhu, Q., Lin, H.S. 2010. Comparing ordinary kriging and regression kriging for soil properties in contrasting landscapes. Pedosphere. 20, 594-606. 